\section{Circadian Fluctuations in Anxiety Disorders}

To the Editor:

Predictable rhythmic fluctuations, especially circadian, have been observed in a wide variety of physiological and psychological functions. Abnormalities of circadian patterns have been documented in people with depression, including a tendency for maximal severity of depression in the morning; however, patients with anxiety or mixed depression/anxiety report a tendency for symptoms to be worse later in the day (Kiloh and Garside 1963; Mendels and Cochrane 1968; Roth et al. 1972; Mathew et al. 1982; Mullaney 1984; Faravelli et al. 1985; Von Zerssen et al. 1985). Despite this observation, no systematic study of potential circadian fluctuations of anxiety in people with clinical anxiety disorders has appeared; that is the purpose of this investigation.

Thirty patients (20 with DSM-III-defined panic attacks and 10 with other anxiety disorders; 23 women; mean age 36 years) at the time of diagnostic evaluation retrospcctively rated their average anxiety level at five different times of day (early morning, late morning, midafternoon, early evening, and late evening) on a 6-point scale (none, very mild, mild, moderate, severe, and very severe) for a good day, an average day, and a bad day for the previous several months. Nineteen of these women who had active menstrual cycles also rated their anxiety on a 5-point scale (worse, somewhat worse, unchanged, somewhat better, and better) at four times during the menstrual cycle (premenstrual week, during menses, postmenstrual week, and midcycle). Finally, all patients who reported panic attacks rated the frequency of attacks that woke them from sleep.

A statistically significant fluctuation in severity of anxiety throughout the day was observed (repeated measures Analysis of Variance: $F=3.30, p<0.05$ ); when only patients with panic attacks were included, the severity level and pattern through the day were very similar. The lowest level was at late morning and the highest early evening, with a fluctuation of approximately one-half of a rating gradation over the five time points (e.g., mild to midway between mild and moderate for an average day). There was also a statistically significant fluctuation over the menstrual cycle, with peak severity (somewhat worse) in the premenstrual week (repeated measures Analysis of Variance: $F=6.70, p<0.01$ ). Forty-five percent of the patients with panic attacks reported that attacks sometimes awoke them from sleep; for these patients, approximately $11 \%$ of the attacks occurred during sleep.

These results demonstrate that, unlike melancholic depression, people with anxiety disorders, particularly panic attacks, tend to experience increased symtoms later in the day. Although the fluctuation through the day was not great, these results are in agreement with the prior unsystematic studies listed above. Menstrually related fluctuations of anxiety severity were also observed. Prior studies of menstrually related fluctuations of anxiety in normal women have produced mixed results (Golub 1976; Alplanalp et al. 1977; Lahmeyer et al. 1982; Veith et al. 1984; Van Den Akker and Steptoe 1985). Although it has been claimed that panic attacks are more likely to occur premenstrually (Rubinow and Roy-Byme 1984), this is the first published documentation. Further study will be necessary to elucidate the mechanisms of the observed fluctuations.

Oliver Cameron

Myung A. Lee

Joan Kotun

Department of Psychiatry

Sheila T. Murphy

University of Michigan

1405 East Ann St.

Ann Arbor, MI 48109

\section{References}

Alplanalp J, Livingston L, Rose RM, Sandwisch D (1977): Cortisol and growth hormone responses to psychological stress during the menstrual cycle. Psychosom Med 39:158.

Faravelli C, LaMalfa G, Romano S (1985): Circadian mythm in primary affective disorder. Compr Psychiatry 26:364.

Golub S (1976): The magnitude of premenstrual anxiety and depression. Psychosom Med 38:4.

Kiloh LG, Garside RF (1963): The independence of neurotic depression and endogenous depression. Br I Psychiatry 109:451.

Lahmeyer AW, Miller M, DeLeon-Jones F (1982): Anxiety and mood fluctuation during the normal menstrual cycle. Psychosom Med 44:183. 
Mathew RJ, Swihart AA, Weinman ML. (1982): Vegetative symptoms in anxiety and depression. Br / Psvchiatry $141: 162$

Mendels J, Cochrine $\mathrm{C}(1968)$ : The nosology of depression The endogenous-reactive concept. Am / Psychiatry 124(suppl): 1 .

Mullaney JA (1984): The relationship hetween anxiety and depression. I Affect Disord 7:1,39

Roth M. Gumey C, Garside RF, Kerr TA (1972): Studies in the classification of affective disorders: The relationship between anxiety states and depressive illnesses-... I. Br. J Pswhiatry 121:147.

Rubinow DR. Roy-Byrne P (1984): Premenstrual syn-
Uromes: Overview from a methodological perspective Am J Psychiatry 141:163

Van Den Akker O. Steptoe A (1985): The pattern and pres alence of symptoms during the menstrual cycle. Br? Prvchiatry 147:164

$V$ eith JL. Anderson J, Slade SA. Thompson P. Langel GR. (ietzlaf $S$ (1984): Plasma $\beta$-endorphin, pain thresholds. and anxiety levels across the human menstrual cycle Phrsiol Behar $32: 31$

Von Zerssen D, Barthelmes H, Dirlick G. Doerr P, Emrich HM. Von Lindon L, Lund R, Pirke KM (1985): Cir adian rhythms in endogenous depression. Pswchiatr $R_{\text {es }} 16: 51$

\section{Lithium and Haloperidol}

To the Editor:

Pandey et al. (1979) showed that phenothiazines enhanced the concentration of lithium (Li) in the red blood cell (RBC). However, the effect of $\mathrm{Li}$ on the concentration of neuroleptics in the RBC has not been studied.

We hypothesized that $\mathrm{Li}$ increases the haloperidol (HAL) concentration in the RBC. In our pilot study of six patients, the addition of $\mathrm{Li}$ to HAL resulted in an increase of HAL in the RBC (Nemes et al. 1985).

We then studied 17 patients with diagnoses of chronic schizophrenia or schizoaffective disorder (DSM-III). Their mean age was 42 years. Average age at first psychiatric hospitalization was 20 years.

The study lasted 10 weeks. In the first week of the study, HAL dose was titrated for each patient to obtain the clinically optimal dose; this dose then re mained fixed for the subsequent 9 weeks. The mean fixed HAL dose was $44 \mathrm{mg}$ daily (range $20-90 \mathrm{mg}$; day). Patients also received placebo $\mathrm{Li}$ during the first 4 weeks of the study; active $\mathrm{Li}$ was added in week 5 . Li plasma levels, ranging from 0.21 to 1.21 meg/liter, were maintained for 4 weeks. Following this period, placebo Li administration was resumed for 2 weeks. Blood levels of HAL and reduced HAL (RHAL) (Korpi et al. 1984) were measured weekly throughout the study. Samples were drawn on 3 con secutive days before active $\mathrm{Li}$ was added (week 4) (in order to establish steady state) and on the last 3 days of the combined HAL-Li period (week 8). Li levels were determined weekly until the end of the study after active $\mathrm{Li}$ was introduced

Table I. Haloperidol and Reduced Haloperidol Concentrations (ng/ml) in Human Blood (Means and Standard Deviations)

\begin{tabular}{|c|c|c|c|c|c|}
\hline & \multicolumn{5}{|c|}{ Treatment } \\
\hline & $\begin{array}{l}\text { Haloperidol } \\
\text { [neck } 4 \text { ! }\end{array}$ & & $\begin{array}{l}\text { Haloperidol lithium } \\
\text { (week } x \text { ) }\end{array}$ & & $\begin{array}{l}\text { Haloperidos } \\
\text { (week if)! }\end{array}$ \\
\hline RBS HAL & $14.1+12.9$ & "' & $15.3+1.3 .9$ & NS & $15.1 \div 129$ \\
\hline RBC Reduced HAL! & $27.6 \pm 77.1$ & NS & $33.5+974$ & $N S$ & $34.3+15.8$ \\
\hline Plasma HAL & $25.2+19.3$ & $\because$ & $27.5 \pm 20.1$ & NS & $25.5+114$ \\
\hline Plasma reduced HAL & $13.0+30.1$ & NS & $17.3 \pm 48.4$ & VS & $19.0 \pm 53$ \\
\hline
\end{tabular}

